\title{
Letter to the Editor: Neurocutaneous Melanosis in Infancy: Always a Dismal Prognosis?
}

\author{
Tayfun HAKAN \\ Fatih Sultan Mehmet Teaching and Research Hospital, Neurosurgery Clinic, Istanbul, Turkey
}

Corresponding author: Tayfun HAKAN tayfunhakan@yahoo.com

\section{Dear Editor,}

I read with great interest the article by Bianci et al. examining neurocutaneous melanosis in infancy with two example cases (2). As mentioned in the article, this rare and complex syndrome-involving the skin and central nervous systemhas a rapid progression and poor prognosis. I would like to contribute to this discussion by sharing the autopsy report of a five-year-old male child who had a fatal giant congenital melanocytic nevus and a malignant melanoma. This report probably was overlooked, as because it was published in Turkish (1).

This child was admitted with stomach pain, progressive leg weakness, and urine and stool incontinence. In addition to numerous congenital melanocytic nevi, he had one giant nevus, which covered nearly $75 \%$ of his trunk. Magnetic resonance imaging revealed a diffuse intradural mass with holocord involvement. An emergency thoracic spine decompression, including laminectomy and partial tumor removal, was performed. Unfortunately, the patient died several days later due to a rapid clinical deterioration. The autopsy revealed a diffuse malignant melanoma infiltrating the spinal leptomeninges, diffuse necrotic areas with melanocytes infiltrating the cerebellum and pons, as well as tumor infiltration into the cerebral cortex, cerebellar subarachnoid, and Virchow-Robin spaces. No hydrocephalus was found. Compound and intradermal nevi were seen in molluscoid and hyperpigmented dermal lesions. The data, including figures of the patient and autopsy findings, can be examined upon demand in the journal's designated web page.

\section{REFERENCES}

1. Aker FV, Karadag N, Hakan T, Aydingoz I, Kilic G, Demirbas MA, Celik L: Neurocutaneous melanosis with malign melanoma of spinal cord: Autopsy report. Türk Nöroșirür Derg 9:66-70, 1999 (in Turkish)

2. Bianchi F, Tamburrini G, Colosimo C, Massimi L, Frassanito $P$ : Neurocutaneous melanosis in infancy: Always a dismal prognosis? Turk Neurosurg 30(4):476-482, 2020 